\title{
Publisher Correction: Laser-accelerated particle beams for stress testing of materials
}

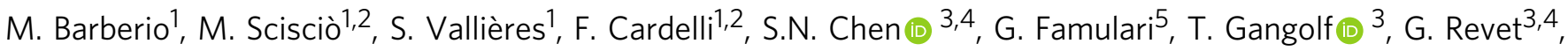 \\ A. Schiavi ${ }^{2}$, M. Senzacqua ${ }^{2} \&$ P. Antici ${ }^{1}$
}

Correction to: Nature Communications https://doi.org/10.1038/s41467-017-02675-x, published online 25 January 2018

The original version of the Supplementary Information associated with this Article contained an error in Supplementary Figure 3, in which all panels, with the exception of the bottom-left 'Ti' panel, were blank. The HTML has been updated to include a corrected version of the Supplementary Information.

Published online: 14 May 2018

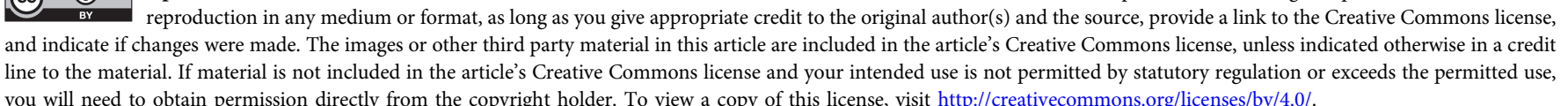

line to the material. If material is not included in the article's Creative Commons license and your intended use is not permitted by statutory regulation or ex
you will need to obtain permission directly from the copyright holder. To view a copy of this license, visit http://creativecommons.org/licenses/by/4.0/.

(C) The Author(s) 2018

\footnotetext{
${ }^{1}$ INRS-EMT, 1650 Boul. Lionel Boulet, Varennes, QC, Canada. ${ }^{2}$ University of Rome "La Sapienza", Dip. SBAl and INFN, Via A. Scarpa 16, 00161 Roma, Italy.

${ }^{3}$ LULI, Ecole Polytechnique, Route de Saclay, 91128 Palaiseau, France. ${ }^{4}$ Institute of Applied Physics, 46 Ulyanov Street, 603950 Nizhny Novgorod, Russia.

${ }^{5}$ Medical Physics Unit, McGill University, Montreal, QC, Canada. Correspondence and requests for materials should be addressed to

P.A. (email: antici@emt.inrs.ca)
} 